University of South Florida

DIGITAL COMMONS

Digital Commons @ University of

@ UNIVERSITY OF SOUTH FLORIDA

South Florida

QMaSC: A Handbook for Directors of

Quantitative and Mathematics Support Centers

USF Libraries

$1-1-2016$

\title{
27. Case Study: The Spinelli Center for Quantitative Learning at Smith College
}

Catherine McCune

Smith College

Follow this and additional works at: https://digitalcommons.usf.edu/qmasc_handbook

\section{Recommended Citation}

Catherine McCune (2016), "Case Study: The Spinelli Center for Quantitative Learning at Smith College", http://dx.doi.org/10.5038/9780977674435.ch27 in G. Coulombe, M. O'Neill, M. Schuckers (Eds.) A Handbook for Directors of Quantitative and Mathematical Support Centers, Neck Quill Press, http://scholarcommons.usf.edu/qmasc_handbook.

This Case Studies is brought to you for free and open access by the USF Libraries at Digital Commons @ University of South Florida. It has been accepted for inclusion in QMaSC: A Handbook for Directors of Quantitative and Mathematics Support Centers by an authorized administrator of Digital Commons @ University of South Florida. For more information, please contact digitalcommons@usf.edu. 


\title{
Case Study: The Spinelli Center for Quantitative Learning at Smith College
}

\author{
(c) Catherine McCune, \\ Smith College
}

口

\section{Introduction}

The Spinelli Center for Quantitative Learning is located in a bright, open space on the second level of Neilson Library, the main humanities library of Smith College. It was originally called the Quantitative Learning Center (QLC), initiated in 2007 through a matching grant from Unbound Philanthropy which helped fund the center's first two and half years. Smith College is a small, liberal arts, college for women, located in the heart of a lively town in Western Massachusetts. Smith has an open curriculum in which there are no distribution requirements, instead almost all requirements are determined by the major. Approximately 2,500 students are on campus in Northampton, while 150 study elsewhere (junior year exchange either abroad or at another college in the USA). The Spinelli Center's mission is to support quantitative material across the curriculum, with the informal motto "We want to help you!"

The space occupied by the Spinelli Center was previously home to narrow stacks of documents and books, which means the space has low concrete ceilings, a surplus of good lighting, and some interesting logistical challenges. The center has two tall cubicle offices, five large group-work spaces, and six computer stations. Four of the group-work spaces have whiteboards and the fifth has a SMART board. The six computers are Macs that dual boot Windows and are equipped with the

Suggested Citation: Catherine McCune (2016), "Case Study: The Spinelli Center for Quantitative Learning at Smith College", http://dx.doi.org/10.5038/9780977674435.ch27 in G. Coulombe, M. O'Neill, M. Schuckers (Eds.) A Handbook for Directors of Quantitative and Mathematical Support Centers, Neck Quill Press, http:// scholarcommons.usf .edu/qmasc_handbook.

This material is based upon work supported, in part, by the National Science Foundation under Grant DUE1255945. Any opinions, findings, and conclusions or recommendations expressed in this material are those of the author(s) and do not necessarily reflect the views of the National Science Foundation 
same software found in the science computer classrooms, with the addition of statistical analysis programs used in the social sciences. The center has no printer, but students can print downstairs in the library's central computer room.

The Spinelli Center directly supports the departments of Chemistry, Economics, Engineering, Physics, Psychology, and Sociology, by employing tutors attached to particular courses or sections of courses. The center indirectly supports courses in the Department of Mathematics and Statistics through general quantitative tutors and through review workshops. Support to other parts of the curriculum is provided by counseling students working on seminar or senior projects that involve data and data analysis and by collaborating with faculty who wish to include quantitative research methods or data-driven class projects in their courses. Students in the Department of Education and Child Study are supported in their licensure process partly through the Math 101 and Math 103 courses, partly through the workshop series "Basic Math Review for Standardized Tests," and partly through individual tutoring sessions. Spinelli Center staff teach Math 101: Algebra, a developmental math course for students who are not prepared to take traditional college level mathematics courses, and Math 103: Math Skills Studio, a two-week intensive review of pre-calculus and calculus offered during the January Term. Refer to "Review Sessions and Classes" in the next section for descriptions of these courses.

\section{Organization and Services}

Students primarily access services provided by the Spinelli Center by dropping in during scheduled tutoring hours or during staff office hours. Some students may also contact tutors via email to arrange an individual or small-group tutoring session. Names of qualified tutors are listed on a bulletin board in the center. Instructors post the email addresses of tutors associated with their courses on their course web pages. Tutoring services are publicized on the Spinelli Center website and on some individual course web pages, and tutors make class visits at the start of the semester to introduce themselves. Tutors are also observers on course Moodle web pages, so the tutors can email students directly (and vice-versa). Additionally, review workshops are coordinated with relevant departments who assist in publicizing them. Services of the Statistics Counselor are advertised through email, class visits, and collaboration with instructors. More details related to these services are given below.

Tutoring (http://www.smith.edu/qlc/tutoring.html )

- Drop-in hours for assistance with general quantitative questions during the day (Monday - Thursday, 9am-10:30am and 12pm-5:30pm; Friday 9am - 1pm) are staffed by Q-tutors (general quantitative tutors). Students who attend these hours tend to seek out help with 
algebra, pre-calculus, calculus, general physics, general chemistry, introductory economics, and introductory statistics.

- Drop-in hours for assistance from a Master Tutor depend on the instructor, course, and tutor. Schedules are regularly updated on the website, with most sessions during the hours 6-10pm, Sunday - Thursday. A student selected as a Master Tutor is attached to each of the following courses: the basic four chemistry courses, the two general physics courses, mathematical methods in physics, the core engineering courses, some elective courses in engineering, the five core courses in economics, statistics for psychology, statistics for sociology, and statistics for government.

- Individual appointments or small-group meetings are available with a Master Tutor, Q-tutor, or with one of the professional staff.

\section{Statistics Counseling}

Students can see the Statistics Counselor for assistance on senior projects and seminar projects that require the collection, management, and/or analysis of data. Instructors can ask the Statistics Counselor for assistance on their own work or obtain training for a student assistant on a data-driven project. Upon request, the Statistics Counselor can give guest lectures such as "An Introduction to Quantitative Methods." Assignments and, if needed, grading rubrics can be provided. Typically, the material for the data assignments is taken directly from the course material and from the students taking the course. The Statistics Counselor can assist in planning statistical projects or assignments and guided statistics lab sessions for life sciences courses in which students collect their own data. Examples of departments where the Statistics Counselor has collaborated are: Afro-American Studies, Anthropology, Biology, Economics, Engineering, Environmental Science and Policy, Exercise and Sports Studies, Government, History, Psychology, Sociology, and Studies of Women and Gender.

\section{Review Workshops and Classes (http://www.smith.edu/qlc/workshops.html)}

Two-hour review sessions on a single topic are the most popular workshop offered. These include the presentation of content and supervised problem practice. The current topics offered each semester are Lines, Logarithms and Exponents, Trigonometric Functions, Differentiation, and Integration. Topical Workshops are scheduled in coordination with instructors in physics, chemistry, and mathematics. For example, the review on integration is scheduled to coincide with the physics topic "Center of Mass."

A series of nine two-hour sessions reviewing basic math topics that are commonly needed in studying for standardized tests (GRE, Massachusetts Teachers Exam for Licensure, etc.) is regularly offered. Seniors and students majoring in education or students wishing to become licensed to 
teach in Massachusetts comprise the target audience for basic mathematics reviews. The sessions are fast-paced, densely packed with material, and no time for solving problems is given. The hope is for students to use the opportunity to do a rough sweep of mental cobwebs and to realize that they need to spend quality time with a study guide and one of the Q-tutors.

Instruction on developmental math topics is given in the four-credit course MTH 101, generically labeled Algebra. The Spinelli Center's Director teaches this course each semester, spending deep, quality time with a few topics (arithmetic, ratios, linear equations, lines, simultaneous equations, triangle trigonometry) and focusing on changing student attitudes around mathematics through group work and coaching. The course attracts a growing number of education majors and social science majors, in addition to the non-traditional aged students for whom the course was originally intended, and also students from a nearby non-traditional college. Math Skills Studio, Math 103, a "boot camp" for review of pre-calculus and some calculus topics offered during the January Term, is co-taught by the Director and the Quantitative Skills Counselor. Math 103 was originally intended for engineering students needing review of pre-calculus and some calculus topics in order to succeed in the general physics courses. The course also welcomes students needing review of pre-calculus in order to succeed in calculus, students needing review of calculus to succeed in intermediate economics courses or in calculus II, or students needing a mathematics course for teacher licensure. The course includes 32 contact hours over two to three weeks. Each session consists of content review and supervised problem solving. Instructors in courses from other departments (for example, Environmental Science and Policy or Sociology) occasionally request a class visit from the Director to give "An Introduction to Excel" lecture.

\section{Online Resources}

The Spinelli Center resources webpage, http://www.smith.edu/qlc/resources.html, contains resources for quantitative content review, for information and inventories related to learning styles, and for math anxiety evaluation and resources.

\section{Q-Skills Assessment}

The Spinelli Center worked with a small group of faculty to develop an online Quantitative Skills Assessment Survey that is given to incoming first-year students and to exiting seniors. The survey has become an annual event, and the office of Institutional Research now collaborates with the Spinelli Center in administrating this survey. The results are intended to eventually help departments assess whether students graduate with adequate quantitative skills appropriate to their major and to determine whether there is a problem with the acquisition of quantitative skills during the students' time at Smith College. 


\section{Staffing, Hiring, and Training}

The professional staff of the Spinelli Center consists of the Director, the Quantitative Skills Counselor, and the Statistics Counselor:

- The Director is a 10-month position that is purely administrative (not faculty). The director reports to the Associate Dean of Faculty, and the position is currently held by someone with a $\mathrm{PhD}$ in pure mathematics. The Director's duties can be roughly grouped into center administration (50\%), faculty/student support and tutoring (20\%), and teaching (30\%).

- The Quantitative Skills Counselor (QS Counselor) is a 9-month position of 231/3 hours per week (0.5 full-time equivalent for 12 months). The QS Counselor reports to the Director, and the position is currently held by someone who already holds a masters degree in geography, holds a bachelors degree in mathematics/environmental science, and is pursuing a masters in biology. The QS Counselor's duties can be roughly grouped into tutor administration (45\%), curriculum support (25\%), teaching (20\%), and center administration (10\%).

- The Statistics Counselor is an hourly position of approximately 10-12 hours/week for about 35 weeks. The Statistics Counselor reports to the Director, and the position is currently held by a graduate student from a nearby university. The Statistics Counselor duties can be grouped as curricular support (65\%), administrative (15\%), outreach (15\%), faculty development and support $(5 \%)$.

The remaining employees of the center are student tutors (approximately 30 per year):

- Q-tutors (general quantitative tutors) are student tutors with a broad background in quantitative courses, usually including at least the first semester of calculus. In addition, Q-tutors often have experience in multivariable calculus, discrete mathematics, or linear algebra, and usually have introductory knowledge in two of chemistry, economics, engineering, physics, and statistics.

- Master Tutors are student tutors attached to a particular course or section. Usually the tutor has taken that particular course.

\section{Hiring}

The student tutors are hired through a process designed to select students who understand content, who have good communication skills, and who will be good employees. The Director and QS Counselor meet with departmental liaisons in late March to discuss plans and needs for the following academic year. The liaisons then solicit names of potential tutors, vet those students within their departments, and return their lists to the Spinelli Center by the end of the first week of April. Often a strong student appears on lists from multiple departments. The Spinelli Center staff solicits applications from those students, holds interviews, and offers positions in a formal email 
after allocating students in a grid of "needed/available" positions. The minimum expectations for tutors are stated in the solicitation letter, on the application, and again in the formal hiring letter. At two of those stages the student acknowledges understanding of the requirements by inserting her initials next to statements such as:

"_ I will attend tutor training on Saturday September 7th from 1-4pm."

The goal is to be done with the hiring process on the last day of classes, usually at the end of April. A few students are asked if they are willing to be back-up tutors in case someone cannot keep their commitment to tutor come the fall. Usually, two tutors need to be replaced over the summer.

\section{Training}

Some informal, subliminal training starts during the interview process. For example, applicants are asked, "What do you do when a student asks you a question beyond the scope of the course, to which you don't know the answer?" If the reply does not include acknowledging that she doesn't know the answer or if the reply does not include referring the student to the instructor for the course, the interviewer points out that this situation could be an excellent way for the tutee to begin an interesting conversation with the instructor and to show the instructor the scope of her thinking.

Training formally starts on the first Saturday of the fall semester from 1-4pm. Approximately 65 student tutors and assistants are trained in this session, around 30 of those are Spinelli Center tutors, and the other 35 are tutors who work for the Mathematics, Statistics, Computer Science, Physics departments, or for the Spatial Analysis Lab. For the first training session of the academic year, the tutors are expected to read the Tutor Training Manual and complete an associated online quiz before coming to the first training session (some tutors use the quiz as a guide for reading the manual, which is consistent with our goal). In this way, the tutors have already covered some administrative topics and basic information around tutoring practices before the training, and the training session time can be devoted to more engaging topics. The training continues in the form of monthly meetings over both semesters, and another large session is held on the first Saturday of the spring semester from $1-4 \mathrm{pm}$.

At the fall training we discuss professionalism, interpersonal boundaries, the expectation that tutors should be "aggressively enthusiastic" about offering help and identifying themselves, the importance of administrative tasks (filling out tutor logs and time sheets), being the face of the center and the academic department that they represent during their shift, FERPA and confidentiality, good and bad non-verbal cues, and scheduling. Waiting time, micro-aggression, how to read a quantitative text, and study skills coaching are additional topics covered during lunch meetings and the spring semester training. The longer training sessions at the beginning of each semester typically involve role-play and discussions led by the returning tutors. 


\section{Assessment}

When a student attends a tutoring session or a workshop, the tutor records the student's name and identification number and then enters it into an online Tutor Log (see the Q-Tutor log http://tinyurl.com/q6w7yqz or the Master Tutor log http://tinyurl.com/qcne62y). These logs help in assessing the usage of the Spinelli Center's various services, identifying scheduling problems, and planning the budget for the following year.

A service evaluation survey is given at the end of each semester to assess the Spinelli Center's tutors and services. The timing of the survey is not ideal because it is given during the last two weeks of the semester. A low response rate is expected from a significant part of the targeted population, resulting in selection bias and other issues. Service is not assessed immediately following a tutoring session because many tutoring sessions (engineering, physics, and introduction to organic chemistry) have 20-30 students in attendance during the 7-9pm session, who are intent on finishing homework that is due the following day. It is unlikely the tutees would take time to fill out a survey, even if it is on paper. Additionally, the cost of the labor to convert paper responses to computerized data would be prohibitive.

The Center plans to analyze possible platforms for more timely ways to administer service surveys, during the academic year 2013-2014.

\section{Community Interactions}

The Spinelli Center has supported students, courses, or instructors in the following departments: Afro-American Studies, Anthropology, Biology, Chemistry, Economics, Education and Child Study, Engineering, Environmental Science and Policy, Exercise and Sports Studies, Government, History, Mathematics and Statistics, Physics, Psychology, Sociology, and Studies of Women and Gender.

The Department of Mathematics and Statistics has its own staff of student tutors called Math TA's and Stats TA's who staff drop-in hours Sunday - Thursday from 7-9pm. The Spinelli Center offers support of mathematics and statistics courses during the day through the Q-tutors and through appointments with the QS Counselor, the Director, and the Statistics Counselor. In this way, the Spinelli Center services complement that of the Math TA's and Stats TA's. The singletopic review sessions offered by the Center are designed to support the mathematics instructors so that less time is spent in class reviewing prerequisite material.

The Spinelli Center has invited the Math TA's and the Stats TA's to the fall tutor training sessions during the past three years, and this has become a good point of collaboration and support. Most recently the invitation has been expanded to include department TA's and student staff from the Department of Computer Science, the Geographic Information Systems (GIS) lab, and the Department of Physics. 
The Spinelli Center can be viewed as the academic twin of the Jacobson Center for Writing, Teaching, and Learning, which used to be the sole academic support center. The Spinelli Center already collaborates with the Jacobson Center (especially with the scientific writing counselor), the Wurtele Center for Work and Life (focused on work-life balance and practical aspects of how to be a student), and the Office for Institutional Research. The Director intends to collaborate with the Sherrard Center for Teaching and Learning (faculty development) and some of the interdisciplinary centers recently established at Smith. The Director of the Spinelli Center is a member of the Statistics Program (a group of instructors from across the curriculum who instruct, supervise or use statistics professionally) and is a member of the advisory board for the academic program Translation Concentration (a concentration is similar to an academic minor but is different because it is interdisciplinary; this concentration stretches across many language and cultural studies departments).

The Director of the Spinelli Center has been a regular participant in the Northeast Consortium on Quantitative Literacy (NECQL) since 2008, and the Spinelli Center (then QLC) hosted the NECQL annual meeting in April 2009. Smith is an institutional member of the National Numeracy Network (NNN), the Director has attended two annual meetings of the NNN, and the Director serves as a reviewer for the NNN's online journal Numeracy. A team from Smith College attended Carleton's PKAL-QuIRK (Project Kaleidoscope-Quantitative Inquiry, Reasoning, and Knowledge) initiative in October 2009, during which they developed short and long range plans, most of which have come to fruition. The Director has helped or mentored other founding directors of new quantitative centers and has served as an external reviewer for established centers.

\section{Acknowledgements}

I thank the Smith College Dean of Faculty, Danielle Ramdath for her support and mentoring, my children for their patience with my working on evenings and weekends, and Viola J. Spinelli for all of the ways that she has supported my growth as an administrator and the center's growth as an integral support service for Smith students. 